\author{
Military Technical College \\ Kobry El-Kobbah, \\ Cairo, Egypt
}

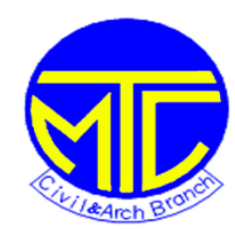

$12^{\text {th }}$ International Conference on Civil and Architecture Engineering

ICCAE-12-2018

\title{
OPTIMIZING BEHAVIOR OF HIGH STRENGTH CONCRETE CONTAINING DIFFERENT RATIOS OF NANO-SILICA FOR DIFFERENT CEMENT CONTENTS
}

\author{
Seleem.S.E.Ahmad ${ }^{1}$, A.Fawzy ${ }^{2}$ and S.A.S.Tleish ${ }^{3}$ \\ 1 Material Engineering Dept., Faculty of Engineering, Zagazig University, Egypt, 01062189843, seleemahmad62@yahoo.com. \\ 2 Material Engineering Dept., Faculty of Engineering, Zagazig University, Egypt. \\ 3 Building \& construction Dept., Faculty of Engineering, Regdalin ,Sebrata University, Libya.
}

\begin{abstract}
Nano technology application has added the effort to improve its properties by altering the microstructure. Nano materials, by virtue of their very small particle size can affect the concrete properties. The use of amorphous Nano silica at different cement contents 500, 600 and $700 \mathrm{Kg} / \mathrm{m} 3$ was studied to improve the compressive strength and tensile strength of high strength concrete. An experimental investigation has been carried out by replacing the cement with Nano silica of $0.5 \%, 1 \%$ and $1.5 \%$ by weight of cement at the different cement contents. The experimental test results showed that concrete prepared with $1 \%$ Nano silica showed a higher strength than those of the $0.5 \%$ and $1.5 \%$ Nano silica at the different cement contents and at 28 and 56 days.
\end{abstract}

\section{INTRODUCTION}

In the present days, Nano silica appears to be one of the attractive cement substitution alternatives for many researchers. Increases in the compressive and tensile strengths of high strength concrete are obtained by the use of Nano silica in concrete mixes. It generally requires admixtures during the mix design as it sets early. Nano silica mixed cement can evolve Nano-crystals of C-S-H gel after hydration. These Nano-crystals fill in the micro pores of the cement concrete hence improving the permeability and strength of concrete. These materials are very effective in altering the properties of concrete at the ultrafine level by the virtue of their very small size. Several researchers have studied the effects of its incorporation on fresh and hardened concrete properties.

Kumar and Sharma (2016) studied the effect of addition of a certain minimum quantity of Nano silica on the increase of compressive strength of concrete. The increase in strength was maximum for Nano silica of $1 \%$ by weight of cement (b.w.c) and least for Nano silica $0.3 \%$ (b.w.c) [1]. Tao Ji (2005) studied the effect of Nano silica on the water permeability and microstructure of concrete. The findings showed that the incorporation of Nano silica can improve the resistance to water of concrete and the microstructure becomes more uniform and compact compared to normal concrete [2]. B.W. Jo et. al. (2007) studied the characteristics of cement mortar with Nano silica particles experimentally and observed higher strength of the splendid mortars for 7 and 28 days. The microstructure analysis showed that Nano silica not only behaves as a filler to improve the microstructure, but also as an activator to the pozzolanic reaction [3].

\section{MATERIALS AND METHODS}

Materials used through this investigation, particularly cement, Nano silica, aggregate, water and chemical admixtures were chosen from the available materials in Egypt. Cement for this 
study is manufactured in Egypt by MBSC (Misr Beni-Suef Cement Co.) is ordinary Portland cement type I of 52.5 grade. The specific gravity of the cement is 3.15. Fine aggregate, locally available river sand (zone-II) confirming to its specifications was used with fineness modulus of 2.95. Coarse aggregate, machine crushed aggregate obtained from the local quarry with max nominal size of coarse aggregate (NMS) was adopted in the present investigation passing sieve $10 \mathrm{~mm}$ and retained on sieve $5 \mathrm{~mm}$ with a specific gravity of 2.64 . Nano silica, amorphous pozzolanic material was used with its reduced size of its spherical particles equal $19.4 \mathrm{~nm}$. The chemical composition of cement and Nano silica fume are given in table (1). Water is free from acids, organic matter, suspended solids and impurities, which when present can adversely affect the strength of concrete.

Table (1) XRD chemical composition percent of cement, and Nano silica.

\begin{tabular}{|c|c|c|c|c|c|c|c|}
\hline & $\mathbf{S i O}_{2}$ & $\mathrm{Al}_{2} \mathbf{O}_{\mathbf{3}}$ & $\mathrm{Fe}_{\mathbf{2}} \mathbf{O}_{\mathbf{3}}$ & $\mathbf{C a O}$ & $\mathbf{M g O}$ & $\mathbf{S O}_{3}$ & L.O.I \\
\hline Cement & 21.5 & 3.68 & 2.76 & 61.5 & 4.8 & - & 1.35 \\
\hline Nano silica & 90.90 & 0.17 & 0.07 & 0.09 & 0.01 & 0.19 & 8.31 \\
\hline
\end{tabular}

\section{Concrete Mix Proportions}

Three types of concrete mixes were used with cement contents (c.c) of 500, 600, and 700 $\mathrm{kg} / \mathrm{m}^{3}$, respectively. For each type four concrete mixes were made. The reference concrete mix without pozzolanic material, a mix with $0.5,1$ and $1.5 \%$ of Nano silica as a partial replacement of cement. For all mixes the water ratio (w/c) was 0.32 . The coarse to fine aggregate ratio (C.a./F.a.) was taken as the common 2:1 ratio. A super plasticizer Galinme (C315) was used in mixes with a percentage of the cement weight to keep almost a constant slump for all mixes of about so that they have the same workability the slump. The absolute volume method was used to the mix proportion for each of the concrete mixes. The mix proportion of the four mixes are shown in table (2). Similar mixes were made for cement contents of 600 and $700 \mathrm{~kg} / \mathrm{m} 3$ and shown in table (3) and (4) respectively.

Cement, fine and coarse aggregates were mixed in the mixer first before adding water to them. The superplasticzer was added to the water and mixed well. Nano silica was added to the mix of water and superplasticzer and they were sonnicated with the ultra-sonic cleaner for about 15 minutes at $37^{\circ} \mathrm{c}$ before these were added to the dry mix.

Table (2) Mix design for concrete mixes of cement content $\left(500 \mathrm{~kg} / \mathrm{m}^{3}\right)$

\begin{tabular}{|c|c|c|c|c|c|c|}
\hline Mix & c.c, $\mathbf{k g} / \mathbf{m}^{3}$ & N.S \% & w/c & C.a./F.a. & NMS of C.a. & superplasticger \% \\
\hline $\mathrm{C}$ & 500 & - & 0.32 & $2: 1$ & $10 \mathrm{~mm}$ & $1.50 \%$ \\
\hline $\mathrm{CN}_{0.5}$ & 450 & 0.5 & 0.32 & $2: 1$ & $10 \mathrm{~mm}$ & $1.50 \%$ \\
\hline $\mathrm{CN}_{1}$ & 495 & 1 & 0.32 & $2: 1$ & $10 \mathrm{~mm}$ & $1.50 \%$ \\
\hline $\mathrm{CN}_{1.5}$ & 445 & 1.5 & 0.32 & $2: 1$ & $10 \mathrm{~mm}$ & $1.50 \%$ \\
\hline
\end{tabular}

Table (3) Mix design for concrete mixes cement content $\left(600 \mathrm{~kg} / \mathrm{m}^{3}\right)$

\begin{tabular}{|c|c|c|c|c|c|c|}
\hline Mix & c.c, $\mathbf{k g} / \mathbf{m}^{\mathbf{3}}$ & N.S \% & w/c & C.a./F.a. & NMS of C.a. & superplasticger \% \\
\hline $\mathrm{C}$ & 600 & - & 0.32 & $2: 1$ & $10 \mathrm{~mm}$ & $2 \%$ \\
\hline $\mathrm{CN}_{0.5}$ & 540 & 0.5 & 0.32 & $2: 1$ & $10 \mathrm{~mm}$ & $2 \%$ \\
\hline $\mathrm{CN}_{1}$ & 594 & 1 & 0.32 & $2: 1$ & $10 \mathrm{~mm}$ & $2 \%$ \\
\hline $\mathrm{CN}_{1.5}$ & 534 & 1.5 & 0.32 & $2: 1$ & $10 \mathrm{~mm}$ & $2 \%$ \\
\hline
\end{tabular}


Table (4) Mix design for concrete mixes cement content $\left(700 \mathrm{~kg} / \mathrm{m}^{3}\right)$

\begin{tabular}{|c|c|c|c|c|c|c|}
\hline $\mathbf{M i x}$ & $\mathbf{C . C}, \mathbf{k g} / \mathbf{m}^{\mathbf{3}}$ & N.S \% & w/c & C.a./F.a. & NMS of C.a. & superplasticger \% \\
\hline $\mathrm{C}$ & 700 & - & 0.32 & $2: 1$ & $10 \mathrm{~mm}$ & $2 \%$ \\
\hline $\mathrm{CN}_{0.5}$ & 630 & 0.5 & 0.32 & $2: 1$ & $10 \mathrm{~mm}$ & $2 \%$ \\
\hline $\mathrm{CN}_{1}$ & 693 & 1 & 0.32 & $2: 1$ & $10 \mathrm{~mm}$ & $2 \%$ \\
\hline $\mathrm{CN}_{1.5}$ & 623 & 1.5 & 0.32 & $2: 1$ & $10 \mathrm{~mm}$ & $2 \%$ \\
\hline
\end{tabular}

RESULTS, ANALYSIS AND
DISCUSSION

\section{Compressive \\ Strength}

Table (5) gives the results of the compressive strength for all the tested specimens at 28 days

$\left(\sigma_{c}\right)$ versus the cement content for all mixes. From data of this figure it can be noticed that the compressive strength of the reference concrete mix increased from $61.8 \mathrm{MPa}$ to 75.8 $\mathrm{MPa}$ at 28 days as the cement content increased from 500 to $700 \mathrm{~kg} / \mathrm{m} 3$. The rate of increase in compressive strength decreased as the cement content increased. The three other mixes containing Nano silica $.5 \%, 1 \%$ and $1.5 \%$, showed the same trend but with higher values of strength. For mixes of $500 \mathrm{~kg} / \mathrm{m}^{3}$ cement content about $5 \%, 17 \%$ and $3 \%$ increase in the

compressive strength at 28 days was obtained in mixes containing Nano silica (N.S) of $0.5 \%, 1 \%$ and $1.5 \%$, respectively, As compared to the strength of reference mix. Similar increases of $5 \%, 14 \%$ and $4 \%$ for $600 \mathrm{~kg} / \mathrm{m} 3$ C.C. mixes and $5 \%, 15 \%$ and $3 \%$ for 700 $\mathrm{kg} / \mathrm{m} 3$ C.C. mixes were obtained. The pozzolanic material (N.S) reacted with the free calcium hydroxide resulting from the hydration of cement compounds, and the resulting compounds filled the inner pores leading to lower permeability and higher ability to resist loads (physical effect). In addition, the resulting compounds were active calcium silicate hydrates which were actually a cementations material increasing the ability to resist high loads (chemical effect).

Table (5) Compressive strength test results of the concrete mixes

\begin{tabular}{|c|c|c|c|c|c|c|c|c|c|c|c|c|c|c|c|}
\hline & \multicolumn{4}{|c|}{$500 \mathrm{~kg} / \mathrm{m}^{3}$ c.c. } & \multirow{3}{*}{$\begin{array}{c}\sigma_{\mathrm{c} 56 /} \\
\sigma_{\mathrm{c} 28}\end{array}$} & \multicolumn{4}{|c|}{$600 \mathrm{~kg} / \mathrm{m}^{3}$ c.c. } & \multirow{3}{*}{$\begin{array}{c}\sigma_{\mathrm{c} 56 /} \\
\sigma_{\mathrm{c} 28}\end{array}$} & \multicolumn{4}{|c|}{$700 \mathrm{~kg} / \mathrm{m}^{3}$ c.c. } & \multirow{3}{*}{$\begin{array}{r}\sigma_{\mathrm{c} 56} \\
\sigma_{\mathrm{c} 28}\end{array}$} \\
\hline & \multicolumn{2}{|c|}{ @ 28 day } & \multicolumn{2}{|c|}{$@ 56$ day } & & \multicolumn{2}{|c|}{ @28 day } & \multicolumn{2}{|c|}{ @ 56 day } & & \multicolumn{2}{|c|}{ @ 28 day } & \multicolumn{2}{|c|}{ @56 day } & \\
\hline Mix & $\begin{array}{c}\sigma_{\mathrm{c}} \\
\mathrm{MPa}\end{array}$ & $\begin{array}{c}\% \\
\text { Relative }\end{array}$ & $\begin{array}{c}\sigma_{\mathrm{c}} \\
\mathrm{MPa}\end{array}$ & $\begin{array}{c}\% \\
\text { Relative }\end{array}$ & & $\begin{array}{c}\sigma_{\mathrm{c}} \\
\mathrm{MPa}\end{array}$ & $\begin{array}{c}\% \\
\text { Relative }\end{array}$ & $\begin{array}{c}\sigma_{\mathrm{c}} \\
\mathrm{MPa}\end{array}$ & $\begin{array}{c}\% \\
\text { Relative }\end{array}$ & & $\begin{array}{c}\sigma_{\mathrm{c}} \\
\mathrm{MPa}\end{array}$ & $\begin{array}{c}\% \\
\text { Relative }\end{array}$ & $\begin{array}{c}\sigma_{\mathrm{c}} \\
\mathrm{MPa}\end{array}$ & $\begin{array}{c}\% \\
\text { Relative }\end{array}$ & \\
\hline Reference & 61.8 & $100 \%$ & 65.5 & $100 \%$ & $106 \%$ & 72.6 & $100 \%$ & 74.7 & $100 \%$ & $103 \%$ & 75.8 & $100 \%$ & 77.2 & $100 \%$ & $102 \%$ \\
\hline $\begin{array}{c}\text { With } 0.5 \% \\
\text { N.S. }\end{array}$ & 64.7 & $105 \%$ & 69.1 & $105 \%$ & $107 \%$ & 75.8 & $105 \%$ & 78.8 & $105 \%$ & $104 \%$ & 80.2 & $105 \%$ & 81.2 & $105 \%$ & $101 \%$ \\
\hline $\begin{array}{c}\text { With } 1 \% \\
\text { N.S. }\end{array}$ & 72.5 & $117 \%$ & 77.1 & $117 \%$ & $106 \%$ & 81.8 & $114 \%$ & 85.8 & $114 \%$ & $105 \%$ & 86.8 & $115 \%$ & 88.1 & $114 \%$ & $102 \%$ \\
\hline $\begin{array}{c}\text { With } 1.5 \% \\
\text { N.S. }\end{array}$ & 63.5 & $103 \%$ & 67.5 & $103 \%$ & $106 \%$ & 74.9 & $104 \%$ & 76.5 & $103 \%$ & $102 \%$ & 77.9 & $103 \%$ & 79.7 & $103 \%$ & $102 \%$ \\
\hline
\end{tabular}




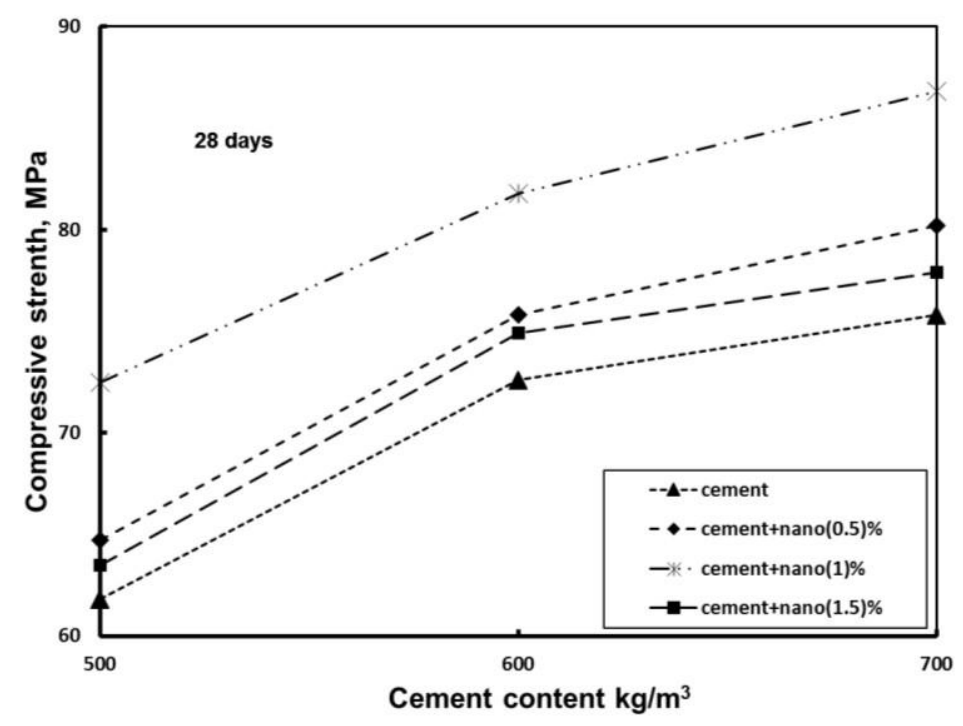

Fig. (1) Compressive strength, $\sigma_{c}$ versus cement content, cc, for different mixes at 28 days

A comparison between the results of the specimens containing Nano silica at different cement contents shows that as the percentage of $\mathrm{N}$ increased from $0.5 \%$ to $1 \%$, the compressive strength increased. However, increasing the N.S content from $1 \%$ to $1.5 \%$ resulted in a decrease in the compressive strength. This may be explained that the higher amount of N.S, which is a replacement of a similar amount of the cement, did not find sufficient $\mathrm{CaOH}$ to react with and thus the strength decreased. In addition the difficulty noticed when sonicating an amount of $1.5 \%$ N.S. may also play a role in reducing the strength.

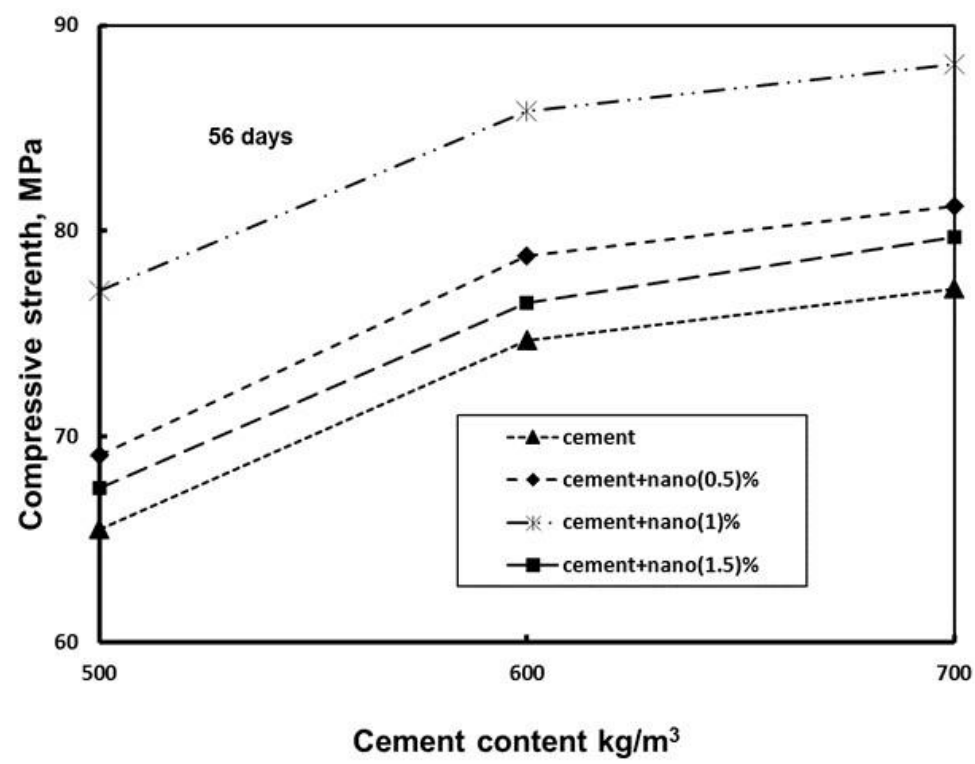

Fig. (2) Compressive strength, $\sigma_{c}$ versus cement content, cc, for different mixes at 56 days

Table (5) and Fig. 2 show the compressive result at 56 days, $\sigma c_{2}$, versus the cement content for all mixes. It is clear that the similar trend of results was obtained as that of 28 days strength. However, slight increases in the strength at 56 days were obtained in the reference mixes of $6 \%, 3 \%$ and $2 \%$ at cement contents of 500,600 and $700 \mathrm{~kg} / \mathrm{m}^{3}$, respectively, as compared to the respective 28 days strength. This is expected as the cement hydrations was continuing with time. Comparable gain of strength was obtained for other mixes containing the pozzolanic materials with the continuality of pozzolanic reaction. The increase in strength 
from 28 to 56 days was $6 \%, 5 \%$ and $2 \%$ in mixes containing $1 \%$ Nano silica for 500,600 and 700 cement content respectively. The Nano size of the pozzolanic material (average diameter $=19.4 \mathrm{~nm}$ ) resulted in higher rate of the pozzolanic reaction and earlier gain of strength than that expected from the pozzolanic material in the micro level. It is also noticed that the gain in strength at 56 days compared to 28 days strength is less as the cement content increased for all mixes.

\section{Splitting Tensile strength}

Table (6) and figs (3) and (4) present the experimental results for the splitting tensile strength of the same above-mentioned concrete mixes of cement content varying from 500 to 700 $\mathrm{kg} / \mathrm{m}^{3}$ at 28 days and at 56 days. It can be seen from Fig. (3) That results of the splitting tensile strength of the concrete mixes at 28 days showed a similar trend to the compressive strength test results as the cement content increased from 500 to $700 \mathrm{~kg} / \mathrm{m}^{3}$. The reference concrete mix showed a gradual increase in the splitting tensile strength at 28 days from 5.7 $\mathrm{MPa}$ to $6.6 \mathrm{MPa}$ as the cement content increased from 500 to $700 \mathrm{~kg} / \mathrm{m}^{3}$. Mixes containing pozzolanic Nano silica showed a similar trend but with higher values of strength due to the pozzolanic reaction. About 3\%, $9 \%$ and $7 \%$ increases in splitting tensile strength at 28 days were obtained in mixes containing $0.5 \%, 1 \%$ and $1.5 \%$ Nano silica, respectively, at cement content of $500 \mathrm{~kg} / \mathrm{m}^{3}$ as compared to the strength of the reference concrete mix. Similar increases were obtained at 600 and $700 \mathrm{~kg} / \mathrm{m}^{3}$ cement content and average of $7.3 \mathrm{MPa}$ splitting tensile strength (103\% of the reference mix) was obtained for the mix containing Nano silica of $1 \%$ at $700 \mathrm{~kg} / \mathrm{m}^{3}$ cement content. This increase is related to the continuing pozzolanic reaction.

Table (6) Splitting tensile strength test results of the concrete mixes

\begin{tabular}{|c|c|c|c|c|c|c|c|c|c|c|c|c|c|c|c|c|}
\hline \multirow[b]{3}{*}{ Mix } & \multirow[b]{3}{*}{ Mix } & \multicolumn{4}{|c|}{$500 \mathrm{~kg} / \mathrm{m}^{3}$ c.c. } & \multirow{3}{*}{$\begin{array}{c}/ \sigma_{156} d \\
\sigma_{128}\end{array}$} & \multicolumn{4}{|c|}{$600 \mathrm{~kg} / \mathrm{m}^{3}$ c.c. } & \multirow{3}{*}{$\begin{array}{l}\sigma_{t 56} d \\
\sigma_{t 28}\end{array}$} & \multicolumn{4}{|c|}{$700 \mathrm{~kg} / \mathrm{m}^{3}$ c.c. } & \multirow{3}{*}{$\begin{array}{c}\sigma_{\mathbf{t 5 6}} / \\
\sigma_{\mathrm{t} 28}\end{array}$} \\
\hline & & \multicolumn{2}{|c|}{ @ 28 day } & \multicolumn{2}{|c|}{ @56 day } & & \multicolumn{2}{|c|}{ @28 day } & \multicolumn{2}{|c|}{ @56 day } & & \multicolumn{2}{|c|}{ @28 day } & \multicolumn{2}{|c|}{ @56 day } & \\
\hline & & $\begin{array}{c}\sigma_{28} \\
\mathbf{M P a}\end{array}$ & $\begin{array}{c}\% \\
\text { Relative }\end{array}$ & $\begin{array}{c}\sigma_{56} \\
\text { MPa }\end{array}$ & $\begin{array}{c}\% \\
\text { Relative }\end{array}$ & & $\begin{array}{c}\sigma_{28} \\
\mathrm{MPa}\end{array}$ & $\begin{array}{c}\% \\
\text { Relative }\end{array}$ & $\begin{array}{c}\sigma_{56} \\
\mathrm{MPa}\end{array}$ & $\begin{array}{c}\% \\
\text { Relative }\end{array}$ & & $\begin{array}{c}\sigma_{28} \\
\mathbf{M P a}\end{array}$ & $\begin{array}{c}\% \\
\text { Relative }\end{array}$ & $\begin{array}{c}\sigma_{56} \\
\mathbf{M P a}\end{array}$ & $\begin{array}{c}\% \\
\text { Relative }\end{array}$ & \\
\hline Reference & C & 5.7 & $100 \%$ & 6 & $100 \%$ & $105 \%$ & 6.2 & $100 \%$ & 6.3 & $100 \%$ & $102 \%$ & 6.6 & $100 \%$ & 6.7 & $100 \%$ & $102 \%$ \\
\hline $\begin{array}{l}\text { With } \\
0.5 \% \\
\text { N.S. }\end{array}$ & $\mathbf{C N}_{0.5}$ & 5.9 & $103 \%$ & 6.3 & $105 \%$ & $107 \%$ & 6.4 & $103 \%$ & 6.6 & $105 \%$ & $103 \%$ & 6.7 & $102 \%$ & 6.8 & $102 \%$ & $102 \%$ \\
\hline $\begin{array}{c}\text { With 1\% } \\
\text { N.S. }\end{array}$ & $\mathbf{C N}_{1}$ & 6.2 & $109 \%$ & 6.5 & $108 \%$ & $105 \%$ & 6.6 & $106 \%$ & 6.8 & $108 \%$ & $103 \%$ & 7.1 & $107 \%$ & 7.3 & $109 \%$ & $103 \%$ \\
\hline $\begin{array}{l}\text { With } \\
1.5 \% \\
\text { N.S. }\end{array}$ & $\mathbf{C N}_{1.5}$ & 6.1 & $107 \%$ & 6.4 & $107 \%$ & $105 \%$ & 6.5 & $105 \%$ & 6.7 & $106 \%$ & $103 \%$ & 6.9 & $105 \%$ & 7.0 & $105 \%$ & $101 \%$ \\
\hline
\end{tabular}

It can also be noticed that the gain in strength due to the presence of pozzolanic material is less in case of splitting tensile strength than in case of compressive strength at the different cement contents. At $500 \mathrm{~kg} / \mathrm{m}^{3}$ cement content $9 \%$ increase in the splitting tensile strength of the $1 \%$ Nano silica concrete mix at 28 days was obtained in comparison to $17 \%$ increase in the compressive strength as compared to the results of the reference mix. This may be explained that the physical effect of pozzolanic materials in filling the pores inside concrete is not effective in case of resisting splitting tensile strength.

Fig. (4) Shows the results of the splitting tensile strength versus the cement content for all mixes. It is clear that similar trend of results was obtained as that of the 28 days strength with a slight increase in the strength due to the continuing cement hydration and pozzolanic reactions with time. 


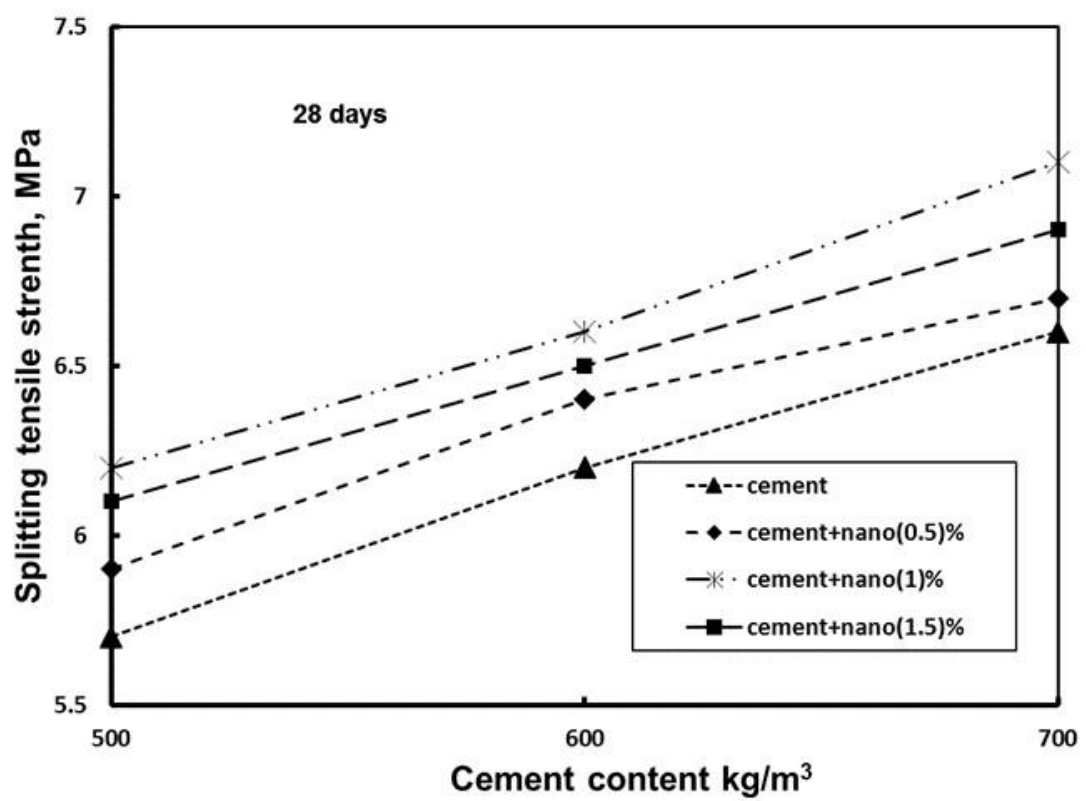

Fig. (3) Splitting tensile strength, $\sigma_{t}$ versus cement content, cc, for different mixes at 28 days

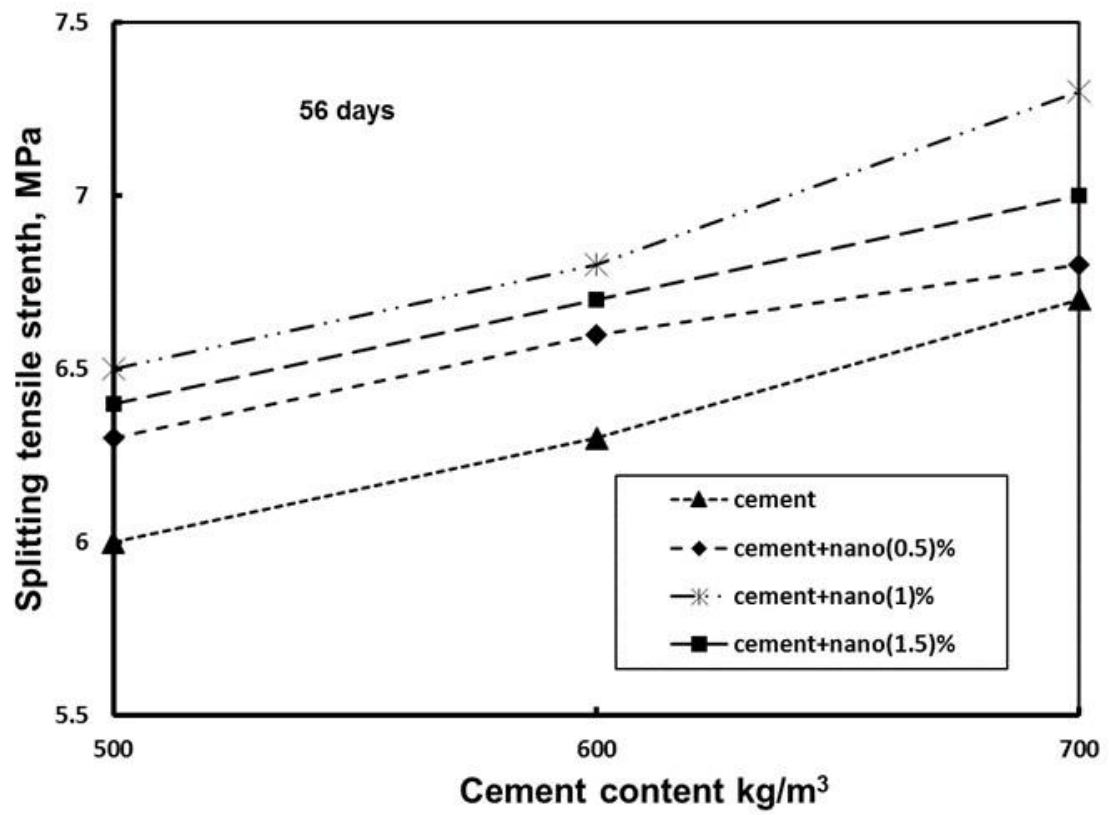

Fig. (4) Splitting tensile strength, $\sigma_{t}$ versus cement content, cc, for different mixes at 56 days 
Relation between compressive and splitting tensile strengths:

Results in table (7), fig. (5) and fig. (6) Verifying that the ratio between $\sigma t$ and $\sigma c$ Tend to the expected results

Table (7) Ratio between $\sigma \mathrm{t}$ and $\sigma \mathrm{c}$

\begin{tabular}{|c|c|c|c|c|c|c|}
\hline & \multicolumn{2}{|c|}{$\mathbf{5 0 0} \mathbf{~ k g / \mathbf { m } ^ { 3 } \text { c.c. }}$} & \multicolumn{2}{c|}{$\mathbf{6 0 0} \mathbf{~ k g / \mathbf { m } ^ { 3 } \text { c.c. }}$} & \multicolumn{2}{c|}{$\mathbf{7 0 0} \mathbf{~ k g} / \mathbf{m}^{3}$ c.c. } \\
\hline & $\mathbf{2 8}$ & $\mathbf{5 6}$ & $\mathbf{2 8}$ & $\mathbf{5 6}$ & $\mathbf{2 8}$ & $\mathbf{5 6}$ \\
\hline $\mathbf{C}$ & 0.09223301 & 0.091603053 & 0.085399449 & 0.084337349 & 0.08707124 & 0.086787565 \\
\hline $\mathbf{C N}_{\mathbf{0 . 5}}$ & 0.091190108 & 0.091172214 & 0.084432718 & 0.083756345 & 0.083541147 & 0.083743842 \\
\hline $\mathbf{C N}_{\mathbf{1}}$ & 0.085517241 & 0.084306096 & 0.080684597 & 0.079254079 & 0.081797235 & 0.082860386 \\
\hline $\mathbf{C N}_{\mathbf{1 . 5}}$ & 0.096062992 & 0.094814815 & 0.086782377 & 0.087581699 & 0.088575096 & 0.08782936 \\
\hline
\end{tabular}

Generally there is a decrease in $\sigma_{t} / \sigma_{\mathrm{c}}$ as cement content increased at 28 days as reported by many investigators [15] and [16] since they stated that as the compressive strength of concrete increased, the tensile strength decreased and consequently there is a decrease in $\sigma_{t} / \sigma_{c}$ Also, there is a similar effect of cement content on $\sigma_{t} / \sigma_{c}$ ratio at 28days and at 56 days for cement mix , and cement+nano as $\sigma_{t} / \sigma_{c}$ decreases from $500 \mathrm{~kg} / \mathrm{m}^{3}$ to $600 \mathrm{~kg} / \mathrm{m}^{3}$ then increased up to $700 \mathrm{~kg} / \mathrm{m}^{3}$ but this increase still less than that of $500 \mathrm{~kg} / \mathrm{m}^{3}$ by comparing fig (5) and fig (6). For the other three mixes, cement, cement+nano, there is steady behavior of $\sigma_{t} / \sigma_{c}$ at 28 days and at 56 days for cement content range from $500 \mathrm{~kg} / \mathrm{m}^{3}$ to $600 \mathrm{~kg} / \mathrm{m}^{3}$ but from $600 \mathrm{~kg} / \mathrm{m}^{3}$ to $700 \mathrm{~kg} / \mathrm{m}^{3}$ the behavior is completely different from 28 days behavior to that of 56days for the same three mixes.

Comparing the test results of compressive strength with those of the tensile strength, it is implied that the increase in the strength due to the presence of $\mathrm{n}_{1}, \mathrm{n}_{0.5}$ and $\mathrm{n}_{1.5}$ was low in the case of tension than in the case of compression. This may be explained that the role of the pozzolanic materials in increasing the strength of the test concrete specimen is low in case of tension than in the case of compression. The physical effect of pozzolanic material (filling the inner pores) has a smaller role in the case of tension. One notices can be taken into consideration is the cost calculation for the mixes of experimental program since the cost of $10 \%$ silica fume mix is lower than that of $1 \%$ Nano silica mix but the strength gained from the $1 \%$ Nano silica mix is still approximately closed to $10 \%$ silica fume mix.

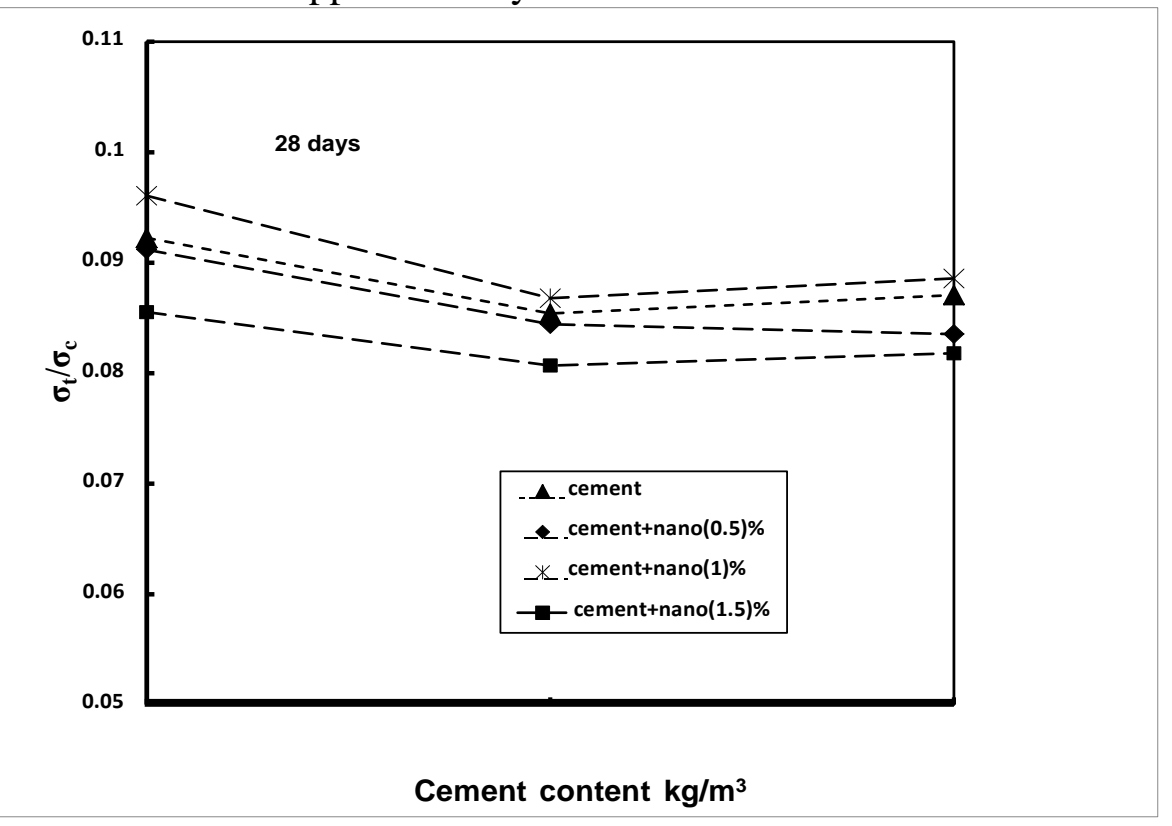

Fig. (5) $\sigma \mathrm{t} / \sigma c$ versus cement content, cc, for different mixes at 28 days 


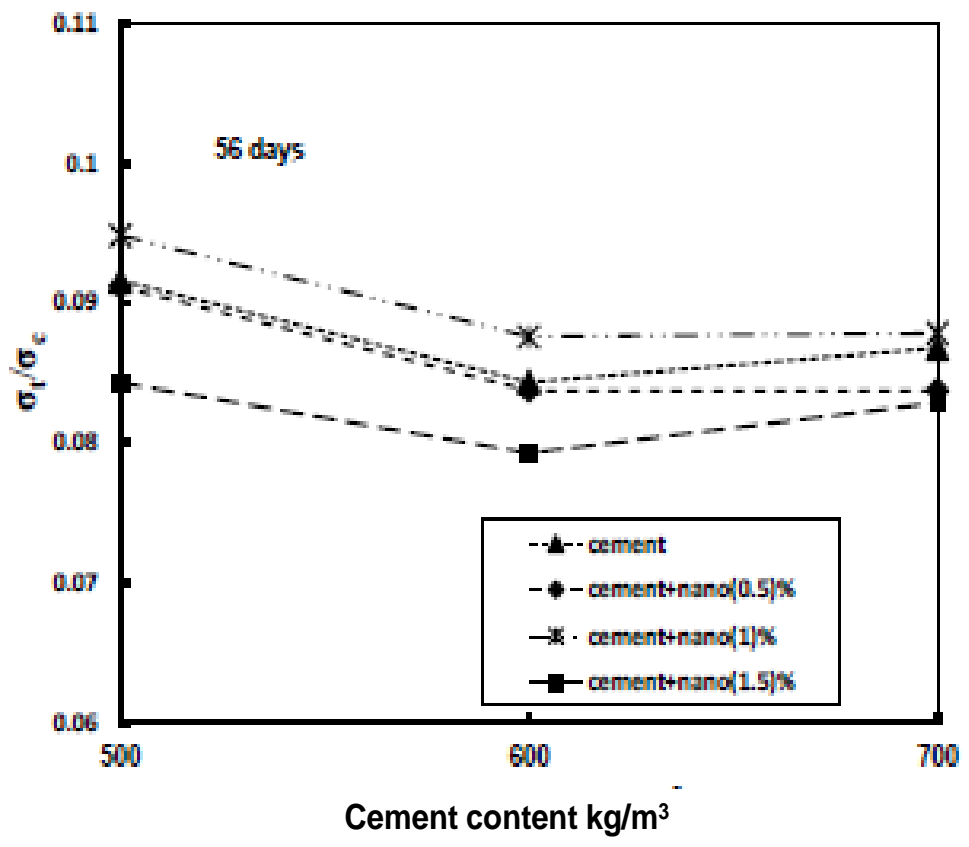

SEM micrograph image and EDX spectrum

Samples used in SEM and EDX spectrum were cut directly from crushed cubes of the control mix and $1 \%$ Nano silica mix, one sample from each their shape was regular and their surface was flat with $500 \mathrm{Kg} / \mathrm{m} 3$ cement content at 90 days.

\section{Hardened cement past of the control mix}

Fig. (7) Shows the porous structure and presence of some micro cracks in the paste found at both low and high magnifications. The main elements found in the Bulk zone of the control paste as given by EDX spectrum were $\mathrm{Ca}, \mathrm{Si}, \mathrm{Al}, \mathrm{Fe}$ and $\mathrm{S}$ with percentage weight 68.26, 16.87, 6.27, 3.93 and 4 respectively. As shown in Fig.(8) $\mathrm{Ca} / \mathrm{Si}$ was estimated and found to be 4.05 indicating a high percentage of $\mathrm{CaO}$ as a relative to the formation of $\mathrm{CaOH}$ due to cement hydration.
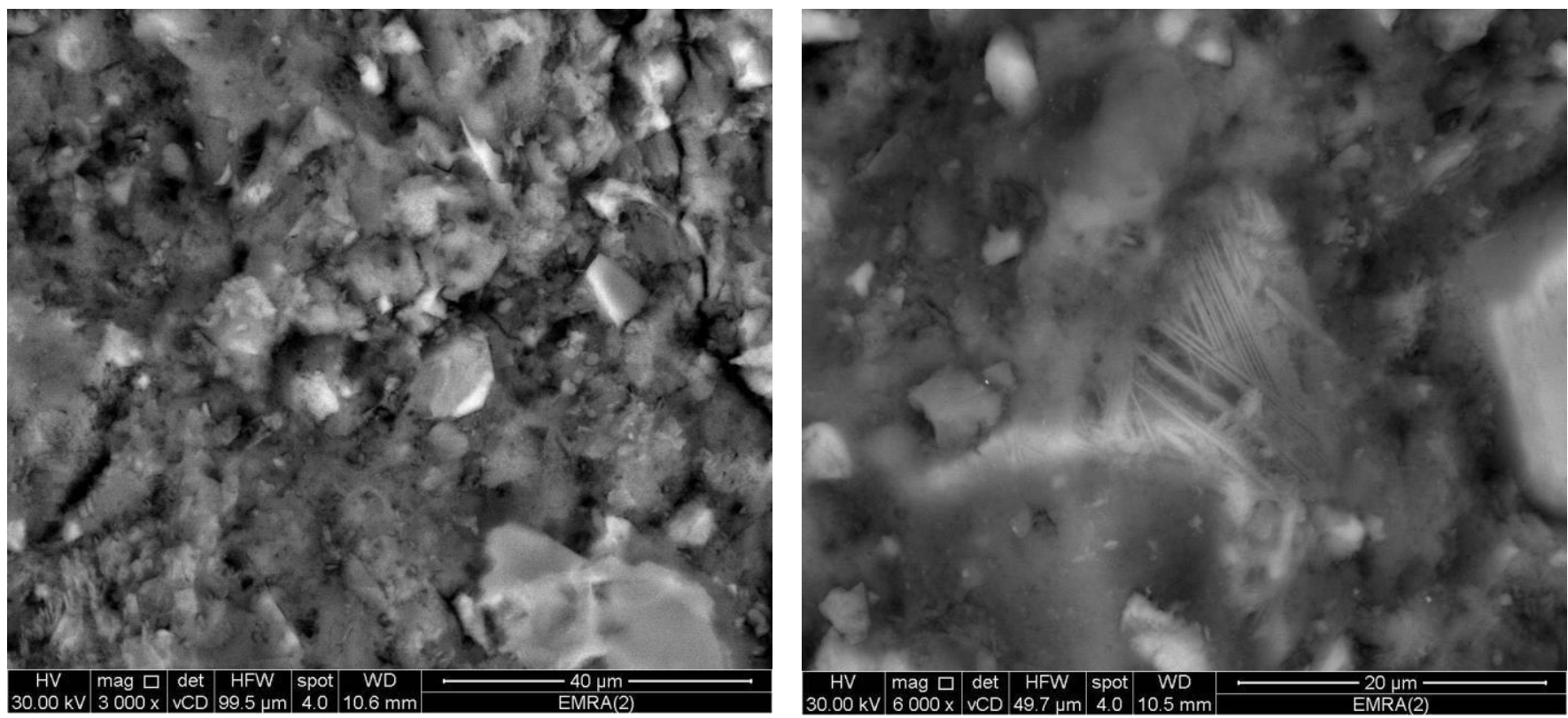

Fig. (7) SEM for control sample micrograph 


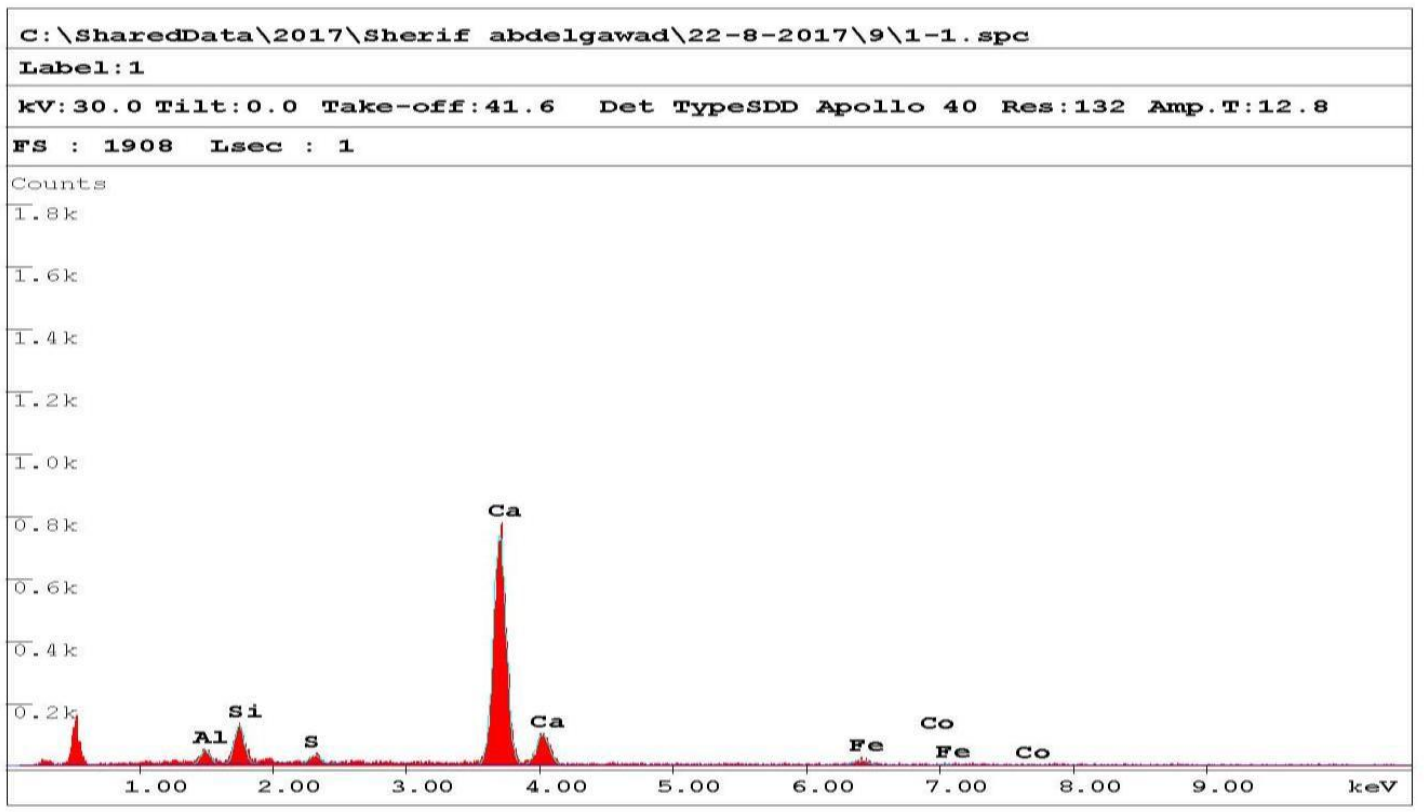

\begin{tabular}{|c|c|c|c|c|c|c|}
\hline Element & Wt \& & Mol 8 & K-Ratio & $z$ & A & E \\
\hline $\begin{array}{r}\text { A1203 } \\
\text { Sion } \\
\text { So3 } \\
\text { CaO } \\
\text { Ee203 } \\
\text { CoO } \\
\text { Total }\end{array}$ & $\begin{array}{r}6.27 \\
15.87 \\
4.00 \\
68.26 \\
3.93 \\
0.67 \\
100.00\end{array}$ & $\begin{array}{r}3.74 \\
17.09 \\
3.04 \\
74.09 \\
1.50 \\
0.54 \\
100.00\end{array}$ & $\begin{array}{l}0.0142 \\
0.0432 \\
0.0115 \\
0.04537 \\
0.0225 \\
0.0043\end{array}$ & $\begin{array}{l}0.9699 \\
0.9991 \\
0.9928 \\
0.9743 \\
0.8989 \\
0.8821\end{array}$ & $\begin{array}{l}0.4382 \\
0.5426 \\
0.7018 \\
0.9528 \\
0.9109 \\
0.9333\end{array}$ & $\begin{array}{l}1.0084 \\
1.0098 \\
1.0279 \\
1.0017 \\
1.0000 \\
1.0000\end{array}$ \\
\hline
\end{tabular}

Fig. (8) EDX spectrum control sample

\section{Hardened cement paste with $1 \%$ Nano silica}

Fig. (9) Shows a lower porous structure with fewer microcracks than that observed in the corresponding control specimen. The main elements found in the bulk zone of the main elements were $\mathrm{Ca}, \mathrm{Al}, \mathrm{Fe}$ and $\mathrm{S}$ with percentage weight 18.37, 76.62, 1.43, 2.53 and 1.04 respectively. As shown in Fig. (10) $\mathrm{Ca} / \mathrm{Si}$ ratio was estimated and found to be 0.24 indicating a high percentage of $\mathrm{SiO} 2$ and a low percentage of $\mathrm{CaO}$ as a result of the presence of Nano silica and its pozzolanic reaction with $\mathrm{CaOH}$.
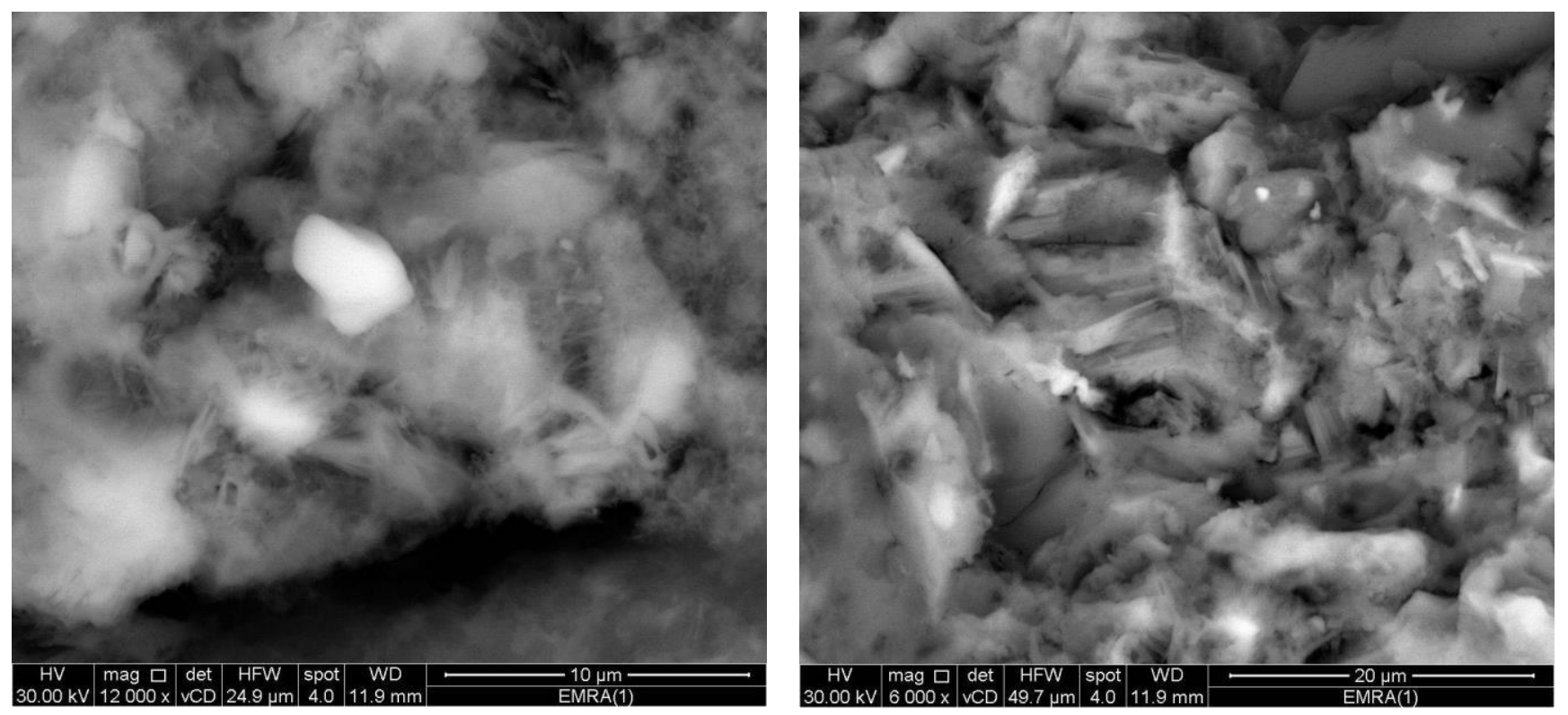

Fig. (9) SEM for Hardened cement paste with $1 \%$ Nano silica 


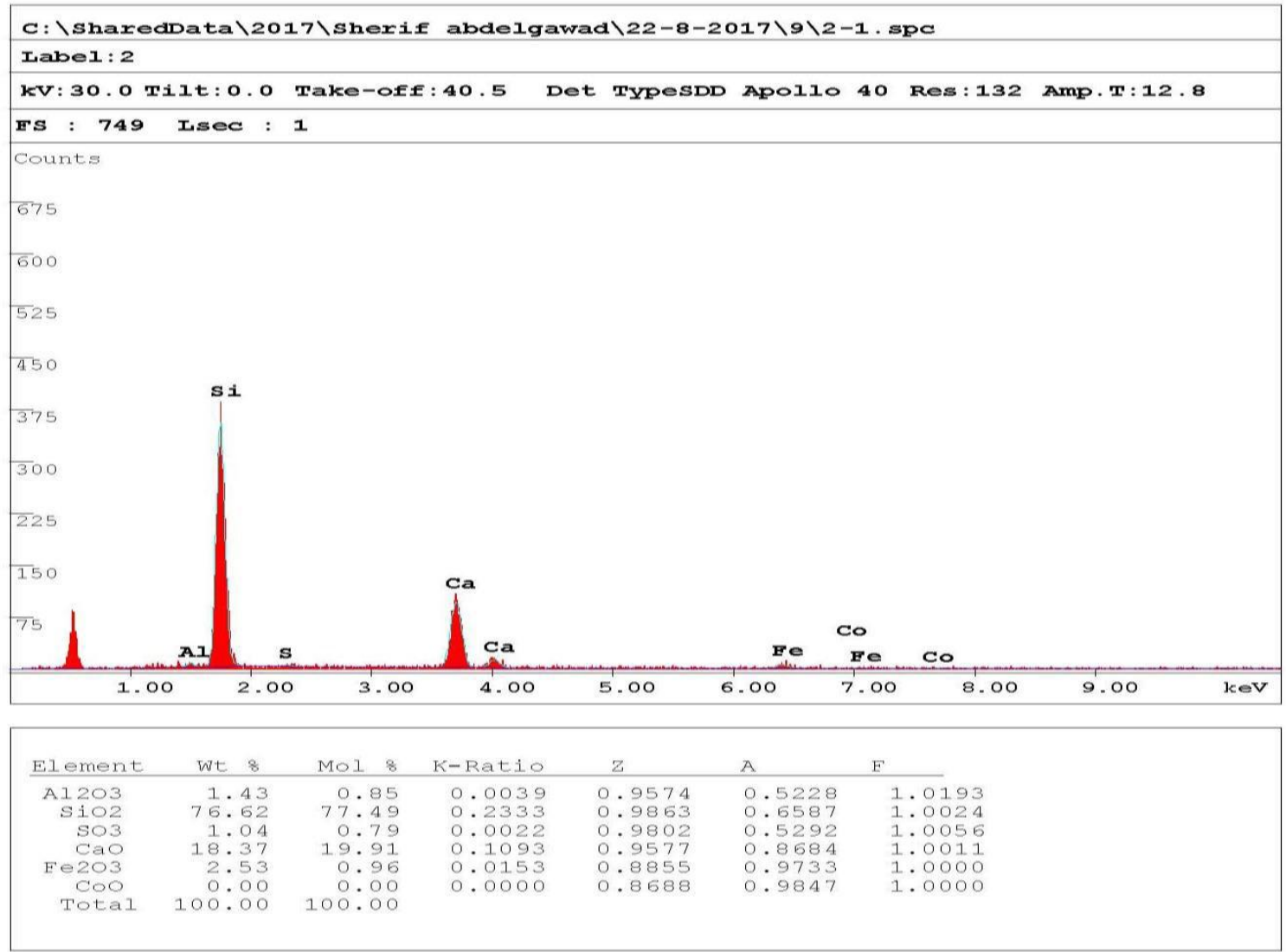

Fig. (10) EDX spectrum Hardened cement paste with $1 \%$ Nano silica

\section{CONCLUSIONS}

Within the scope of this study the following conclusions can be drown:

1- The addition of Nano silica as a partial replacement of the cement content resulted in an increase in the compressive and splitting tensile strength up to $1 \%$ due to its pozzolanic reaction.

2- Further addition of Nano silica to $1.5 \%$ resulted in a decrease in the strength, which may be related to the insufficient quantity of $\mathrm{CaOH}$ required to complete the pozzolanic reaction.

3- An increase in the compressive strength at 28 days of about $17 \%, 14 \%$ and $15 \%$ was obtained due the addition of $1 \%$ Nano silica at 500,600 and $700 \mathrm{~kg} / \mathrm{m}^{3}$ cement contents as compared to the reference cement mix.

4- An increase in the splitting tensile strength at 28 days of about $9 \%, 6 \%$ and $7 \%$ was obtained due to the addition of $1 \%$ Nano silica at 500,600 and $700 \mathrm{~kg} / \mathrm{m}^{3}$ cement contents as compared to the reference cement mix.

5- The reference concrete mix showed an increase in the 56 days compressive strength of about $6 \%, 3 \%$ and $2 \%$ for 500,600 and $700 \mathrm{~kg} / \mathrm{m}^{3}$ cement contents as compared to the 28 day compressive strength. Obtained values for the splitting tensile strength were $5 \%, 2 \%$ and $2 \%$.

6- Mixes containing Nano silica of $0.5 \%, 1 \%$ and $1.5 \%$ showed an increase in the strengths at 56 days in the range of that of the reference concrete mix as compared to the 28 day strengths. 


\section{REFERENCES:}

[1] Dharmendra Kumar and Nishant Sharma, "Study of compressive strength of concrete using Nano silica", journal of Ceramics and Concrete Sciences, 2016, volume1, issue 2, page 1-11.

[2] Tao Ji "Preliminary study on the water permeability and micro structure of concrete incorporating Nano silica ", Cement and Concrete Research, 2005, 35:1943-1947.

[3] Byung-Wan Jo, Chang-Hyun Kim and Ghi-ho Tae, "Characteristics of cement mortar with Nano silica particles", Construction and Building Materials, 2007, 21:1351-1355.

[4] M. Nili, A. Ehsani and K. Shabani, "Influence of Nano silica and micro silica on concrete performance", Second International Conference on Sustainable Construction Materials and TechnologiesJune 28 - June 30, 2010.

[5] Ali Nazari, Shadi Riahi and Shirin Riahi, "Embaded nanoparticles mechanical properties monitoring in cemenitious composites", Journal of American Science, 6(4): , 2010, 86-89.

[6] Ali Nazari, Shadi Riahi and Shirin Riahi, "Improvement of the mechanical properties of the cementitious composites by using nanoparticles", Journal of American Science, 6(4): 2010, 98-101.

[7] Ali Nazari, Shadi Riahi and Shirin Riahi, "Mechanical properties of cement mortar with Al2O3 nanoparticles", Journal of American Science, 6(4): 2010, 94-97.

[8] Alireza Naji Givi, Suraya Abdul Rashid and Farah Nora A. Aziz, "Experimental investigation of the size effects of $\mathrm{SiO} 2$ Nano particles on the mechanical properties of binary blended concrete", composite Part B: Engineering Volume 41, Issue 8, December 2010, 673-677.

[9] G. Quercia and H. J. H. Brouwers., " Application of Nano silica in concrete mixtures", $8^{\text {th }}$ fib PhD symposium in Kgs. Lyngby, Denmark, 2010.

[10] M.S. Morsy, S.H. Alsayed and M. Aqel, "Effect of Nano clay on mechanical properties and microstructure of ordinary Portland cement mortar", International Journal on Civil Engineering \& Environmental Engineering, 10(01), 2010, 21-25.

[11] Shekari, A. H. and Razzaghi, M., "Influence of Nano particles on durability and mechanical properties of SCC with GGBFS as binder", Procedia Engineering, 14: (2011), 3036-3041. 